\title{
Two Small Molecules, ZCL278 and AZA197 Show Promise in Influencing Protein Interactions Involving the Ras-Related Protein Cell division cycle 42 [Cdc42] to Modulate Its Oncogenic Potential
}

\author{
Djamali Muhoza, Paul D. Adams* \\ Department of Chemistry and Biochemistry, The University of Arkansas, Fayetteville, AR, USA \\ Email: *pxa001@uark.edu
}

How to cite this paper: Muhoza, D. and Adams, P.D. (2017) Two Small Molecules, ZCL278 and AZA197 Show Promise in Influencing Protein Interactions Involving the Ras-Related Protein Cell division cycle 42 [Cdc42] to Modulate Its Oncogenic Potential. Open Journal of Biophysics, 7, 71-81.

https://doi.org/10.4236/ojbiphy.2017.73006

Received: March 8, 2017

Accepted: May 12, 2017

Published: May 15, 2017

Copyright $\odot 2017$ by authors and Scientific Research Publishing Inc. This work is licensed under the Creative Commons Attribution International License (CC BY 4.0).

http://creativecommons.org/licenses/by/4.0/

\begin{abstract}
Cdc42 is a member of the Rho subfamily of Ras-related proteins, which were among the first oncogenic proteins to be identified as playing a significant role in a variety of cellular events [Barbacaid, 1987, Ann. Rev. Biochem]. Equally important, Protein-Protein Interactions [PPIs] involving Cdc42 continue to highlight the role of Ras-related proteins' relevance to cancer. As these proteins have been considered incapable of being "druggable", due to a perceived lack of binding surface[s] that are amenable to small molecule targeting, there remains limited development of therapies to tackle diseased states caused by Cdc42-stimulated hyperactivity. Thusly, it has become important to characterize molecular details, including dynamics, of PPIs involving Cdc42 that may lend themselves as potential targets for therapeutic approaches. Recently, two small molecules, ZCL278 and AZA197, have shown promise in directly targeting Cdc42 to influence PPIs that are capable of causing Cdc42-stimulated abnormal signaling. In this editorial, we highlight recent studies that show case how these two small molecules may influence Cdc42-protein interactions.
\end{abstract}

\section{Keywords}

Ras [Rat Sarcoma], Small Molecule Target, Cdc42, Protein-Protein Interactions

\section{Introduction}

Ras-relatd GTPases can be involved in cell-signaling processes that underlie their roles in diseased states such as cancer [1]. In addition, these proteins are involved in cell-signaling activities that are vital to processes such as cell prolife- 
ration, and differentiation, that, if not properly regulated, can lead to hyperactivity [2]. This underlies their importance as targets for drug discovery efforts to control Ras-stimulated abnormal cell signaling [3]. Cell division cycle 42 [Cdc42] is a member of the Rho subfamily of Ras-related proteins. Mutations, abnormal expression or protein interactions involving $\mathrm{Cdc} 42$ have been characterized to play significant roles in events leading to cellular proliferation, inhibition of cell death, and cell transformation for quite some time [4]. As such, Cdc42 is a model protein system to characterize molecular details of Ras-related Protein-Protein Interactions [PPIs]. Progress has been made in understanding the pathogenesis of Cdc42-stimulated hyperactivity [5]. However, targeting small molecules towards PPIs involving Cdc42 have remained difficult, mainly because of the challenges in determining the most appropriate binding interfaces on the protein to target [6] [7]. Strategies that will impact the development of future target-based design should showcase new molecular features of Cdc42 and its PPIs in cell signaling pathways that facilitate cell proliferation and transformation, tumor invasion, and metastasis. Furthermore, it is important to understand whether structural "wavering", or dynamics, which has been shown to play a critical role in the ability of Cdc42 to interact with different effectors and regulators [8] [9] [10] [11], can be exploited by small molecule targeting "directly" to influence PPIs and interrupt abnormal cell signaling.

Specifically targeting Cdc42 for therapeutic purposes has seen some recent progress [12] [13] [14], and a few reviews have highlighted the promise of these new approaches [5] [15]. Cdc42, which is post-translationally modified to target the periphery of the inner cell membrane where it functions, cycles between active GTP-bound and inactive GDP-bound states, and this process is regulated by PPIs with effector/regulatory proteins (Figure 1). Interactions with Guanine nucleotide Exchange Factors [GEFs] influence GDP dissociation and GTP binding, which activates the protein. Interactions with GTPase-Activating Proteins [GAPs] stimulate the intrinsic GTPase activity of Ras that leads to the inactive GDP bound form of the protein. Cdc42 interactions with Guanine Dissociation Inhibitors [GDIs] result in the inhibition of GDP dissociation from the protein. Cdc42 has a six-stranded $\beta$-sheet, five $\alpha$-helices, and a guanine nucleotidebinding site with a conserved sequence that recognizes the guanine base, the $\beta$-phosphate and a magnesium ion [16] [17]. There are two important conformationally dynamic regions, known as Switch 1 and Switch 2 that are involved in the binding of effectors to Cdc42 [8] [10] [11] [16] [18] [19] [20] [21] [22]. Targeting these protein-binding surfaces to influence Cdc42 involved PPIs, while still a daunting challenge, remains vital as Cdc42-stimulated hyperactivity has been a hallmark of this protein's involvement in various cancers [23]. In addition, members of the Ras-related family of proteins have been referred to as "undruggable", partly because some of the earliest structural models did not reveal surface-accessible binding regions available for targeting [24] [25]. It should be noted that studies characterizing the conformational dynamics of Ras-related proteins have revealed two conformational states exhibited by the Switch 1 


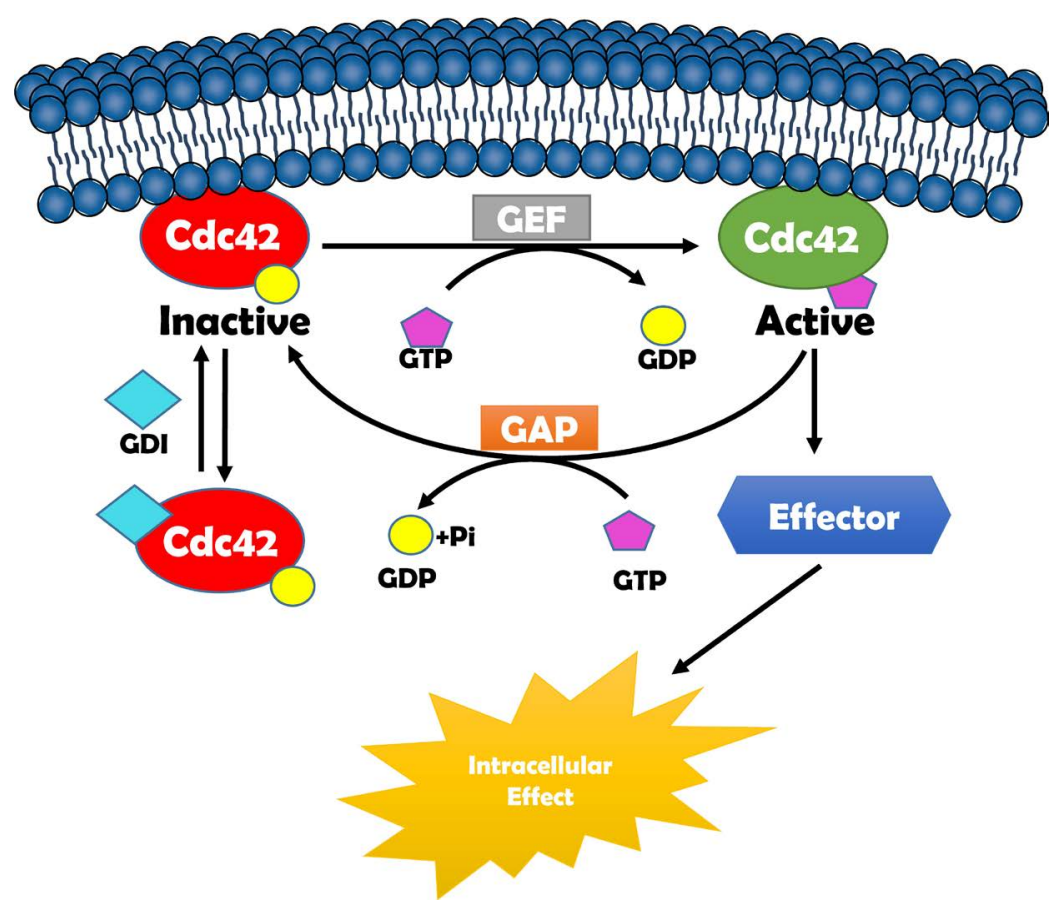

Figure 1. Schematic of cyclic activity between active [GTP-bound] Cdc42 and inactive [GDP-bound] Cdc42. Interactions involving: Guanine nucleotide exchange factor [GEF] [Gray-shaded], GTPase-activating effector protein [GAP] [Orange-shaded], and Guanine dissociation inhibitor [GDI] [Light Blue-shaded] are highlighted. Effector interactions leading to other intracellular signaling effects are also shaded [Dark Blue-shaded].

region, one state that binds strongly to effectors and the other that binds effectors weakly [8] [9] [26]. These findings strongly suggest that an important approach to combating Ras-related abnormal cell-signaling should involve the targeting of binding interfaces, such as Switch 1 in Cdc42, with small molecules to potentially disturb PPIs with effectors that might lead to hyperactivity (Figure 2) [1] [5] [6] [7] [26]-[32].

Targeting PPIs involving Cdc42 directly in dynamic regions such as Switch 1 should also foster the modulation of unwanted interactions leading to Cdc42stimulated hyperactivity without disturbing the nucleotide-binding pocket. However, targeting Cdc42 PPIs could encompass extensive binding interface regions between the proteins of interest. In addition, the conformational changes needed to bring the proteins together might make the binding interface unfeasible for smaller molecules to bind or influence the PPI [6]. Peptides have been employed in attempts to overcome this hurdle, due to their structural similarities to their targeted proteins of interest, as well as their larger size that may help cover binding interfaces [6]. However, peptides have proven to be a formidable challenge due to their limited ability to cross the cell membrane [6]. It is promising to consider that structural characterizations of PPIs involving Cdc42 might also reveal critical residues within the binding interface that could be compromised by a small molecule target. Furthermore, these residues might not need to occupy large surfaces on the protein to influence the PPI. Recent biophysical and biochemical studies, using $\mathrm{Cdc} 42$, have characterized the structurally dynamic 


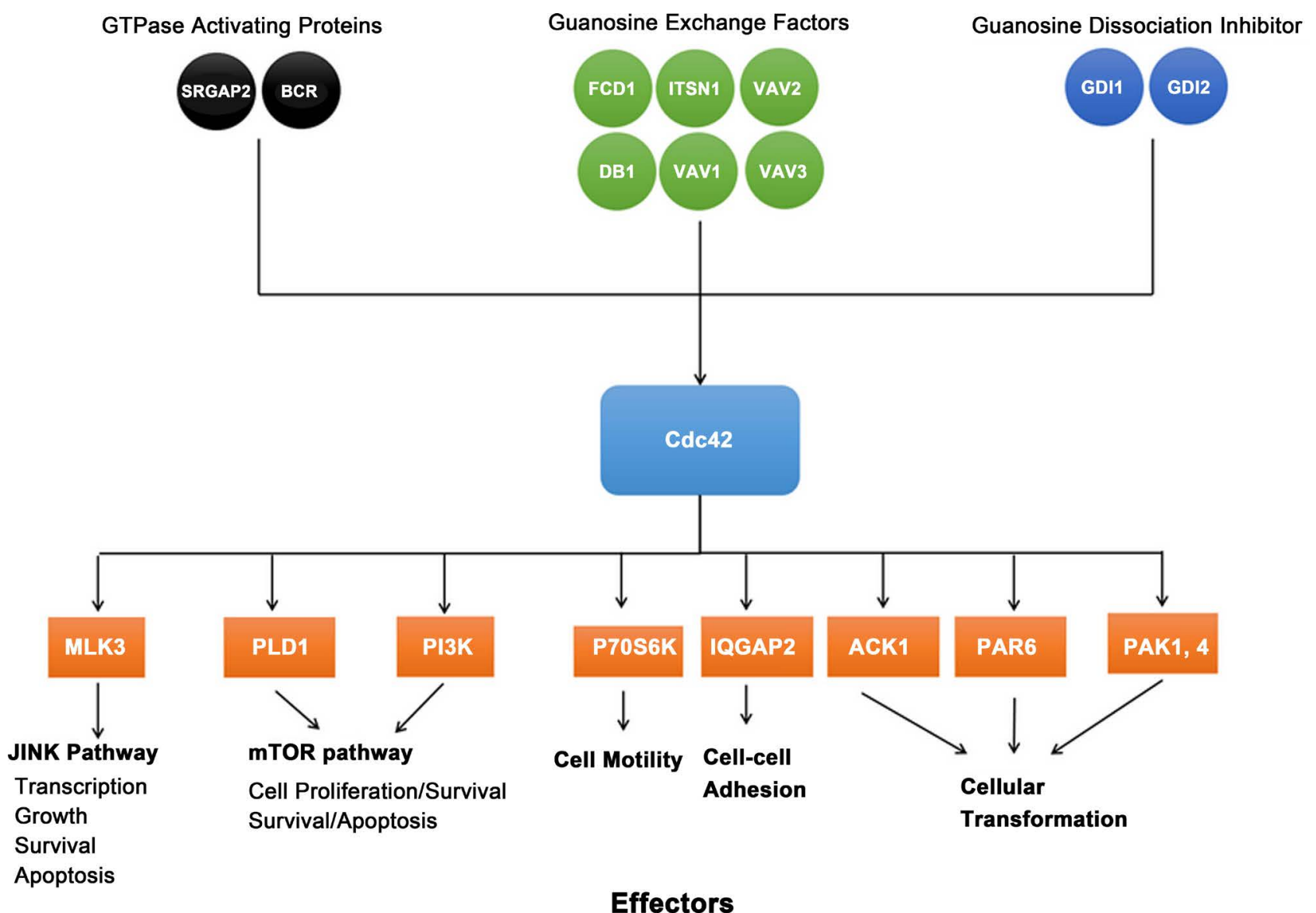

Figure 2. Illustration of GAP, GEF, GDI and downstream effector interactions known to lead to Cdc42-stimulated hyperactivity. Figure designed based on data presented in reference [5].

Switch 1 region that serves as the binding interface for a GTPase inhibitor protein that fosters Cdc42 hyperactive state [10] [11]. These studies suggested that Switch 1 could serve as a prime region for small molecule targeting to modulate Cdc42 structure and conformational dynamics that may influence PPIs. Therefore, it is important to highlight the need for continued development of therapeutic approaches to target PPIs involving Cdc42.

\section{Small Molecule Targeting of Cdc42 PPIs}

As mentioned previously, Cdc42 has become a model Ras-related system to aid our understanding of important molecular details of protein interactions with its effectors and regulatory proteins due to the abnormal cell signaling effects that may arise if these PPIs are not regulated (Figure 3(a)). In particular, interactions with GEFs are needed to initiate nucleotide exchange required for Cdc42 activation, due to the protein's high affinity for GDP [33] [34]. However, the GTPbound state of the protein must be properly regulated in order to prevent hyperactivity. Therefore, modifying GEF interactions has provided an exciting approach for potential therapeutic regulation by small molecules [7]. Recently, Friesland et al., used high throughput in silico screening to identify one molecule, 4-[3-[2-[4-Bromo-2-chloro-phenoxy]-acetyl]-thioureido]-N-[4,6-dimethyl- 

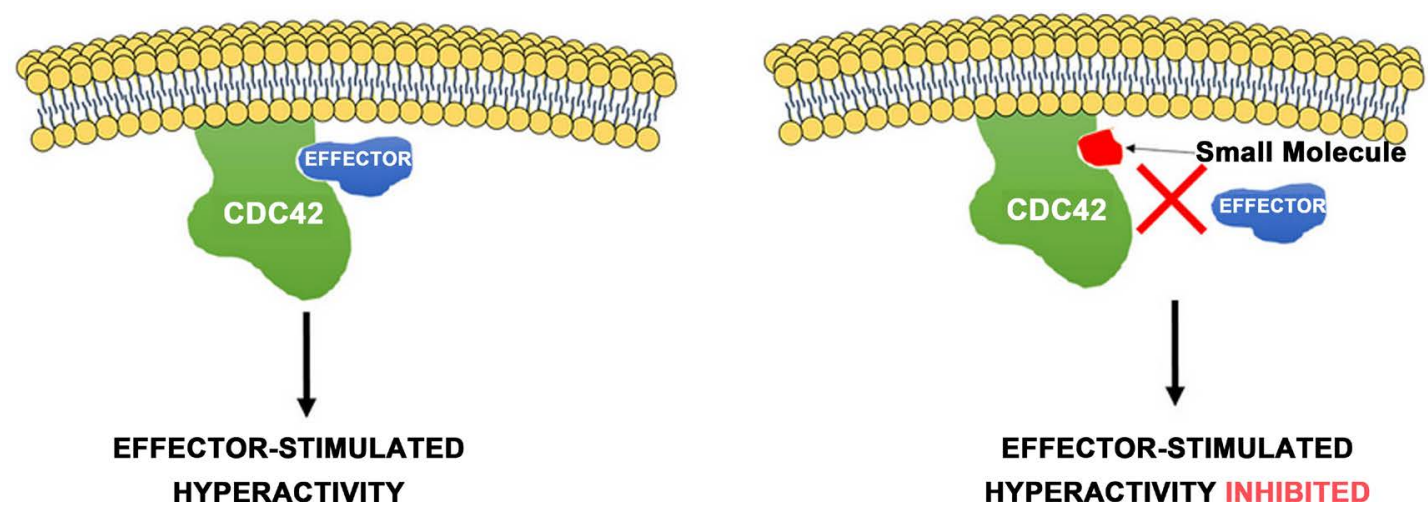

EFFECTOR-STIMULATED HYPERACTIVITY HYPERACTIVITY INHIBITED

(a)

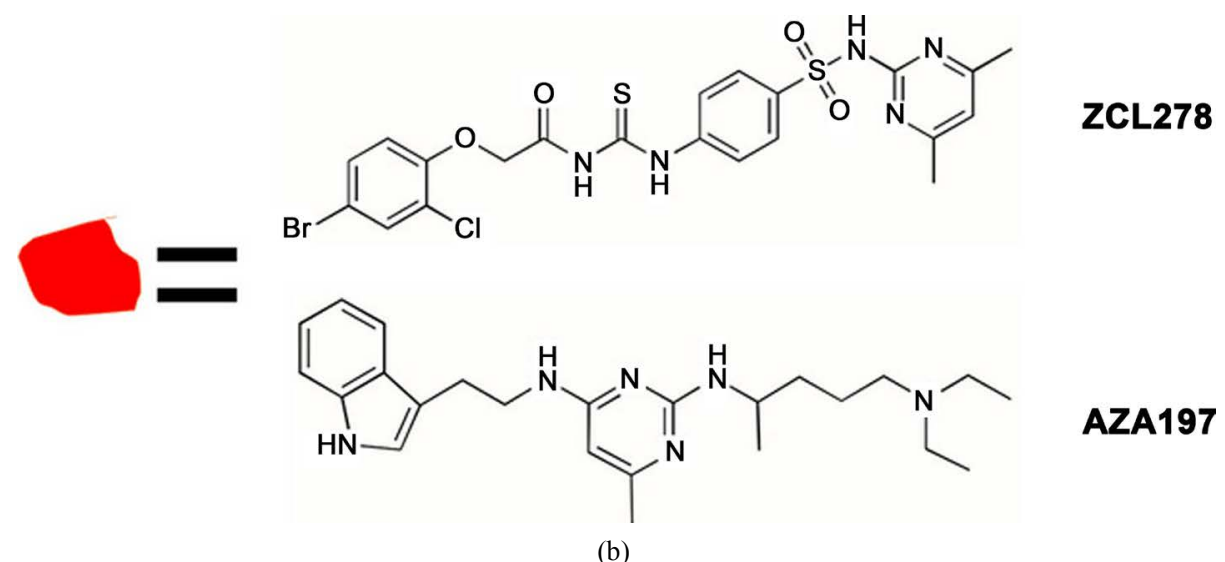

Figure 3. (a) Illustrating the concept of inhibiting effector-stimulated Cdc42 hyperactivity by using a small molecule. (b) Molecular structures of ZCL278 and AZA197.

pyrimidin-2-yl] benzenesulfonamide, known as ZCL278 (Figure 3(b)), that could target the Switch 1 binding pocket of Cdc42 and "mimic" an interaction between Cdc42 and a GEF, Intersectin [12]. Results revealed that the Cdc42ZCL278 interaction suppressed several Cdc42-stimulated functions including abolishment of microspike formation, a reduction of perinuclear accumulation of active Cdc42, Cdc42-regulated neuronal branching, and actin-stimulated motility. Furthermore, the specificity of this small molecule for Cdc42 was compared to NSC23766, a known Rac (another member of the Ras superfamily) inhibitor. In vivo results suggested that only ZCL278 was able to inhibit Cdc42 function [12].

Molecular details of the Cdc42-ZCL278 interaction are currently still lacking. Nevertheless, Friesland et al. [12] did confirm direct binding of ZCL278 to Cdc42 using fluorescence spectroscopy and surface plasmon resonance, as $\mathrm{K}_{\mathrm{d}}$ values were found to be in the low $\mu \mathrm{M}$ range. Moreover, poses taken after in silico docking of the small molecule to Cdc42 suggested that ZCL278 could interact with several residues in the Switch 1 region that are key to the Cdc42- Intersectin interaction [12]. While experimental validation is still needed, these findings highlight that the Switch 1 binding region may serve as a prime region for small molecules to bind and possibly alter Cdc42-effector interactions. Studies from this laboratory have characterized how backbone dynamics changes in 
the Switch 1 region of a Cdc42 variant can alter a protein interaction with a peptide derivative of a GTPase inhibitor and restore normal GTP hydrolytic activity [10]. Therefore, it should be possible for a small molecule such as ZCL278 to bind to the Switch 1 region in Cdc42 and change its structure or alter backbone dynamics of the protein to disturb or block the Cdc42-effector PPI. Subsequent experiments to test these possibilities will certainly provide valuable insight into the Cdc42-ZCL278 interaction. Overall, the work of Friesland, et al., highlighted ZCL278 as a possible prime target toward the Switch 1 region of Cdc42.

The previously mentioned compound NSC23766 was also used to identify another small molecule that has shown promise as a potential therapeutic agent against Cdc42-stimulated hyperactivity leading to colorectal cancers [35] [36]. Through virtual screening studies, derivatives of NSC23766 revealed that N2-[4-Diethylamino-1-methyl-butyl]-N4-[2-[1H-indol-3-yl]-ethyl]-6-methyl-py rimidine-2,4-diamine, known as AZA197 (Figure 3(b)), influenced Cdc42- stimulated function [13]. Results from the experiments of Zins et al. showed that AZA197 could target GTP-bound Cdc42 and inhibit Cdc42-stimulated hyperactivity, as characterized by the suppression of proliferation of SW620 colon cancer cells, a reduction of the migration and invasion potential of these cells, and the inhibition of cell growth in vivo [13]. In vitro studies showed that the small molecule inhibited a Cdc42-GEF interaction involving Dbs, a Dbl guanine nucleotide exchange factor homolog that also interacts with Cdc42 in the Switch 1 region [37], as judged by sharp changes in the fluorescence intensity of a fluorescent guanine nucleotide derivative, [2'-[or-3']-O-[N-Methylanthraniloyl]-GDP [Mant-GDP] [13]. This result suggested that AZA197, like ZCL278, might target the Switch 1 region of Cdc42 to modulate PPIs that could potentially stimulate Cdc42 over-activity. Moreover, Cdc42 signaling pathways involving binding to the downstream effector PAK1, and its involvement in ERK pathway were down regulated by AZA197 [13]. These studies highlighted the potential influence that the small molecule AZA197 could have on a PPI that leads to Cdc42-stimulated hyperactivity. However, further development will be needed in the use of AZA197 because, due to toxicity, only low $\mu \mathrm{M}$ concentrations of the small molecule could be used [13]. Zins et al., also pointed out that, at concentrations > $20 \mu \mathrm{M}$, this molecule destroyed the plasma membrane of SW620 and HT-29 colon cancer cells, as well as S3T3 fibroblast cells. Therefore, significant challenges remain.

\section{Summary and Future Considerations}

Ras-related proteins, such as Cdc42, play crucial roles in the regulation of cell signaling [38]. Therefore, the proper regulation of these proteins, in the face of events that facilitate unwanted activity, remains important. In this editorial, we have highlighted recent findings on two small molecules that alter Cdc42- stimulated hyperactivity by binding to specific sites on the protein where PPIs occur. ZCL278 binds to the Switch 1 region of Cdc42 and shows the potential to mimic a GEF protein interaction that renders the protein unable to be activated 
via nucleotide exchange [12]. In addition, AZA197 appears to block an interaction between Cdc42 and a GEF [Dbs] in-vitro [13]. In both cases, evidence suggested that targeting these small molecules to binding surfaces where Cdc42 PPIs occur might be a viable approach to regulating Cdc42-stimulated hyperactivity. Moreover, these studies suggested that the small molecules could possibly be targeted to these binding surfaces without disturbing the structural integrity of the nucleotide-binding active site of $\mathrm{Cdc} 42$. The logical next steps in uncovering the influence that these small molecules could potentially have on Cdc42 involved PPIs should involve the structural elucidation of Cdc42 bound to each of these small molecules. The results of these experiments can be expected to be vital in contributing information on the conformational and/or dynamics differences in important binding regions of Cdc42 that might be influenced by small molecules such as ZCL278 and AZA197. Nonetheless, results of the studies discussed indicate that it is promising to consider that there may be surfaces within the structural framework of Cdc42, and possibly other Ras-related proteins, that could be susceptible to small molecule targeting to help modulate abnormal cell-signaling activity. Finally, in addition to strategies that use small molecules to directly bind and influence PPIs, it may be also important to consider the use of small molecules as potential protein binding targets to restrict conformational flexibility as an approach to disturb PPIs that lead to Ras-stimulated hyperactivity.

\section{Acknowledgements}

We thank Drs. Roger Koeppe II, Robert Oswald and Miss Alix Montoya- Beltrand for providing critical feedback and suggestions on the content and scope of this manuscript, and Dr. Mahmoud Moradi who assisted with figure design. This publication was supported by Grant Number 1K-01-CA113753 to P.D.A. from the National Cancer Institute of the National Institutes of Health [NIH], the Arkansas Science and Technology Authority, and the Arkansas Biosciences Institute.

\section{References}

[1] Lin, Y. and Zheng, Y. (2015) Approaches of Targeting Rho GTPases in Cancer Drug Discovery. Expert Opinion on Drug Discovery, 10, 991-1010. https://doi.org/10.1517/17460441.2015.1058775

[2] Smith, M.J., Neel, B.G. and Ikura, M. (2013) NMR-Based Functional Profiling of RASopathies and Oncogenic RAS Mutations. Proceedings of the National Academy of Sciences of the United States of America, 110, 4574-4579. https://doi.org/10.1073/pnas.1218173110

[3] Johnson, C.W. and Mattos, C. (2013) The Allosteric Switch and Conformational States in Ras GTPase Affected By Small Molecules. Enzymes, 33, 41-67. https://doi.org/10.1016/B978-0-12-416749-0.00003-8

[4] Bos, J.L. (1989) Ras Oncogenes in Human Cancer: A Review. Cancer Research, 49, 4682-4689.

[5] Arias-Romero, L.E. and Chernoff, J. (2013) Targeting Cdc42 in Cancer. Expert Opin 
Ther Targets, 17, 1263-1273. https://doi.org/10.1517/14728222.2013.828037

[6] Mullard, A. (2012) Protein-Protein Interaction Inhibitors Get into the Groove. Nature Reviews Drug Discovery, 11, 173-175. https://doi.org/10.1038/nrd3680

[7] Spiegel, J., Cromm, P.M., Zimmermann, G., Grossmann, T.N. and Waldmann, H. (2014) Small-Molecule Modulation of Ras Signaling. Nature Chemical Biology, 10, 613-622. https://doi.org/10.1038/nchembio.1560

[8] Spoerner, M., Herrmann, C., Vetter, I.R., Kalbitzer, H.R. and Wittinghofer, A. (2001) Dynamic Properties of the Ras Switch I Region and Its Importance for Binding to Effectors. Proceedings of the National Academy of Sciences of the United States of America, 98, 4944-4949. https://doi.org/10.1073/pnas.081441398

[9] Spoerner, M., Hozsa, C., Poetzl, J.A., Reiss, K., Ganser, P., Geyer, M. and Kalbitzer, H.R. (2010) Conformational States of Human Rat Sarcoma [Ras] Protein Complexed with Its Natural Ligand GTP and Their Role for Effector Interaction and GTP Hydrolysis. The Journal of Biological Chemistry, 285, 39768-39778. https://doi.org/10.1074/jbc.M110.145235

[10] Morris, K.M., Henderson, R., Suresh Kumar, T.K., Heyes, C.D. and Adams, P.D. (2016) Intrinsic GTP Hydrolysis Is Observed for a Switch 1 Variant of Cdc42 in the Presence of a Specific GTPase Inhibitor. Small GTPases, 7, 1-11.

https://doi.org/10.1080/21541248.2015.1123797

[11] Chandrashekar, R., Salem, O., Krizova, H., McFeeters, R. and Adams, P.D. (2011) A Switch I Mutant of Cdc42 Exhibits Less Conformational Freedom. Biochemistry, 50, 6196-6207. https://doi.org/10.1021/bi2004284

[12] Friesland, A., Zhao, Y., Chen, Y.H., Wang, L., Zhou, H. and Lu, Q. (2013) Small Molecule Targeting Cdc42-Intersectin Interaction Disrupts Golgi Organization and Suppresses Cell Motility. Proceedings of the National Academy of Sciences of the United States of America, 110, 1261-1266. https://doi.org/10.1073/pnas.1116051110

[13] Zins, K., Gunawardhana, S., Lucas, T., Abraham, D. and Aharinejad, S. (2013) Targeting Cdc42 with the Small Molecule Drug AZA197 Suppresses Primary Colon Cancer Growth and Prolongs Survival in a Preclinical Mouse Xenograft Model by Downregulation of PAK1 Activity. Journal of Translational Medicine, 11, 295. https://doi.org/10.1186/1479-5876-11-295

[14] Zins, K., Lucas, T., Reichl, P., Abraham, D. and Aharinejad, S.A (2013) Rac1/Cdc42 GTPase-Specific Small Molecule Inhibitor Suppresses Growth of Primary Human Prostate Cancer Xenografts and Prolongs Survival in Mice. PLoS One, 8, e74924. https://doi.org/10.1371/journal.pone.0074924

[15] Chandrashekar, R. and Adams, P.D. (2013) Prospective Development of Small Molecule Targets to Oncogenic Ras Proteins. Open Journal of Biophysics, 3, 207-211. https://doi.org/10.4236/ojbiphy.2013.34025

[16] Feltham, J.L., Dotsch, V., Raza, S., Manor, D., Cerione, R.A., Sutcliffe, M.J., Wagner, G. and Oswald, R.E. (1997) Definition of the Switch Surface in the Solution Structure of Cdc42Hs. Biochemistry, 36, 8755-8766. https://doi.org/10.1021/bi970694x

[17] Prior, I.A., Lewis, P.D. and Mattos, C. (2012) A Comprehensive Survey of Ras Mutations in Cancer. Cancer Research, 72, 2457-2467.

https://doi.org/10.1158/0008-5472.CAN-11-2612

[18] Bourne, H.R., Sanders, D.A. and McCormick, F. (1990) The GTPase Superfamily: A Conserved Switch for Diverse Cell Functions. Nature, 348, 125-132. https://doi.org/10.1038/348125a0

[19] Diaz, J.F., Escalona, M.M., Kuppens, S. and Engelborghs, Y. (2000) Role of the Switch II Region in the Conformational Transition of Activation of Ha-ras-p21. 
Protein Science, 9, 361-368. https://doi.org/10.1110/ps.9.2.361

[20] Fidyk, N.J. and Cerione, R.A. (2002) Understanding the Catalytic Mechanism of GTPase-Activating Proteins: Demonstration of the Importance of Switch Domain Stabilization in the Stimulation of GTP Hydrolysis. Biochemistry, 41, 15644-15653. https://doi.org/10.1021/bi026413p

[21] Krengel, U., Schlichting, L., Scherer, A., Schumann, R., Frech, M., John, J., Kabsch, W., Pai, E. and Wittinghofer, A. (1990) Three-Dimensional Structures of H-Ras p21 Mutants: Molecular Basis for Their Inability to Function As Sifnal Switch Molecules. Cell, 62, 539-548. https://doi.org/10.1016/0092-8674(90)90018-A

[22] Sutcliffe, M., Feltham, J., Cerione, R. and Oswald, R. (1994) Model Building Predicts an Additional Conformational Switch When GTP Binds to the Cdc42Hs Protein. Protein and Peptide Letters, 1, 84-91.

[23] Barbacid, M. (1987) Ras Genes. Annual Review of Biochemistry, 56, 779-827. https://doi.org/10.1146/annurev.bi.56.070187.004023

[24] Pai, E.F., Kabsch, W., Krengel, U., Holmes, K.C., John, J. and Wittinghofer, A. (1989) Structure of the Guanine Nucleotide Binding Domain of the Ha-Ras Oncogene Product p21 in the Triphosphate Conformation. Nature, 341, 209-214. https://doi.org/10.1038/341209a0

[25] Pai, E.F., Krengel, U., Petsko, G.A., Goody, R.S., Kabsch, W. and Wittinghofer, A. (1990) Refined Crystal Structure of the Triphosphate Conformation of h-ras p21 at $1.35 \AA$ A Resolution: Implication for the Mechanism of GTP Hydrolysis. The EMBO Journal, 9, 2351-2359.

[26] Rosnizeck, I.C., Graf, T., Spoerner, M., Trankle, J., Filchtinski, D., Herrmann, C., Gremer, L., Vetter, I.R., Wittinghofer, A., Konig, B. and Kalbitzer, H.R. (2010) Stabilizing a Weak Binding State for Effectors in the Human Ras Protein by Cyclen Complexes. Angewandte Chemie International Edition, 49, 3830-3833. https://doi.org/10.1002/anie.200907002

[27] Gonzalez-Perez, V., Reiner, D.J., Alan, J.K., Mitchell, C., Edwards, L.J., Khazak, V., Der, C.J. and Cox, A.D. (2010) Genetic and Functional Characterization of Putative Ras/Raf Interaction Inhibitors in C. Elegans and Mammalian Cells. Journal of Molecular Signaling, 5, 2. https://doi.org/10.1186/1750-2187-5-2

[28] Kato-Stankiewicz, J., Hakimi, I., Zhi, G., Zhang, J., Serebriiskii, I., Guo, L., Edamatsu, H., Koide, H., Menon, S., Eckl, R., Sakamuri, S., Lu, Y., Chen, Q.Z., Agarwal, S., Baumbach, W.R., Golemis, E.A., Tamanoi, F. and Khazak, V. (2002) Inhibitors of Ras/Raf-1 Interaction Identified By Two-Hybrid Screening Revert Ras-Dependent Transformation Phenotypes in Human Cancer Cells. Proceedings of the National Academy of Sciences of the United States of America, 99, 14398-14403.

https://doi.org/10.1073/pnas.222222699

[29] Arkin, M. (2005) Protein-Protein Interactions and Cancer: Small Molecules Going in for the Kill. Current Opinion in Chemical Biology, 9, 317-324. https://doi.org/10.1016/j.cbpa.2005.03.001

[30] Waldmann, H., Karaguni, I.M., Carpintero, M., Gourzoulidou, E., Herrmann, C., Brockmann, C., Oschkinat, H. and Muller, O. (2004) Sulindac-Derived Ras Pathway Inhibitors Target the Ras-Raf Interaction and Downstream Effectors in the Ras Pathway. Angewandte Chemie International Edition, 43, 454-458. https://doi.org/10.1002/anie.200353089

[31] Wang, W., Fang, G. and Rudolph, J. (2012) Ras inhibition Via Direct Ras Binding-Is There a Path Forward? Bioorganic \& Medicinal Chemistry Letters, 22, 57665776. https://doi.org/10.1016/j.bmcl.2012.07.082

[32] Scott, D.E., Ehebauer, M.T., Pukala, T., Marsh, M., Blundell, T.L., Venkitaraman, 
A.R., Abell, C. and Hyvonen, M. (2013) Using a Fragment-Based Approach to Target Protein-Protein Interactions. Chembiochem: A European Journal of Chemical Biology, 14, 332-342. https://doi.org/10.1002/cbic.201200521

[33] John, J., Rensland, H., Schlichting, I., Vetter, I., Borasio, G.D., Goody, R.S. and Wittinghofer, A. (1993) Kinetic and Structural Analysis of the Mg[2+]-Binding Site of the Guanine Nucleotide-Binding Protein p21H-ras. The Journal of Biological Chemistry, 268, 923-929.

[34] John, J., Sohmen, R., Feuerstein, J., Linke, R., Wittinghofer, A. and Goody, R.S. (1990) Kinetics of Interaction of Nucleotides with Nucleotide-Free H-ras p21. Biochemistry, 29, 6058-6065. https://doi.org/10.1021/bi00477a025

[35] Espina, C., Cespedes, M.V., Garcia-Cabezas, M.A., Gomez del Pulgar, M.T., Boluda, A., Oroz, L.G., Benitah, S.A., Cejas, P., Nistal, M., Mangues, R. and Lacal, J.C. (2008) A Critical Role for Racl in Tumor Progression of Human Colorectal Adenocarcinoma Cells. The American Journal of Pathology, 172, 156-166.

https://doi.org/10.2353/ajpath.2008.070561

[36] Gomez del Pulgar, T., Bandres, E., Espina, C., Valdes-Mora, F., Perez-Palacios, R., Garcia-Amigot, F., Garcia-Foncillas, J. and Lacal, J.C. (2007) Differential Expression of Rac1 Identifies Its Target Genes and Its Contribution to Progression of Colorectal Cancer. The International Journal of Biochemistry \& Cell Biology, 39, 22892302. https://doi.org/10.1016/j.biocel.2007.06.014

[37] Rossman, K.L., Worthylake, D.K., Snyder, J.T., Siderovski, D.P., Campbell, S.L. and Sondek, J. (2002) A Crystallographic View of Interactions between Dbs and Cdc42: PH Domain-Assisted Guanine Nucleotide Exchange. The EMBO Journal, 21, 13151326. https://doi.org/10.1093/emboj/21.6.1315

[38] Zimmermann, G., Papke, B., Ismail, S., Vartak, N., Chandra, A., Hoffmann, M., Hahn, S.A., Triola, G., Wittinghofer, A., Bastiaens, P.I. and Waldmann, H. (2013) Small Molecule Inhibition of the KRAS-PDEdelta Interaction Impairs Oncogenic KRAS Signalling. Nature, 497, 638-642. https://doi.org/10.1038/nature12205 


\section{Abbreviations and Acronyms}

Ras: Rat Sarcoma

Cdc42: Cell division cycle 42

PPI: Protein-Protein Interactions

GEF: Guanine nucleotide Exchange Factors

GTP: Guanosine triphosphate

GDP: Guanosine diphosphate

Kd: Dissociation Constant

GAP: GTPase-Activating Protein

GDI: Guanine Dissociation Inhibitor

DBS: Diazepam binding inhibitor

Mant-GDP : [2'-[or-3']-O-[N-Methylanthraniloyl]-GDP [Mant-GDP]

AZA197: N2-[4-Diethylamino-1-methyl-butyl]-N4-[2-[1H-indol-3-yl]-ethyl]-6methyl-pyrimidine-2,4-diamine

ZCL278: 4-[3-[2-[4-Bromo-2-chloro-phenoxy]-acetyl]-thioureido]-N-[4,6-dimethyl-pyrimidin-2-yl] benzenesulfonamide

NSC23766: N6-[2-[[4-[Diethylamino]-1-methylbutyl]amino]-6-methyl-4-pyrimidinyl]-2-methyl-4,6-quinolinediamine trihydrochloride N6-[2-[[4-[Diethylamino]-1-methylbutyl]amino]-6-methyl-4-pyrimidinyl]-2-methyl-4,6-quinolinediamine trihydrochloride

Submit or recommend next manuscript to SCIRP and we will provide best service for you:

Accepting pre-submission inquiries through Email, Facebook, LinkedIn, Twitter, etc. A wide selection of journals (inclusive of 9 subjects, more than 200 journals)

Providing 24-hour high-quality service

User-friendly online submission system

Fair and swift peer-review system

Efficient typesetting and proofreading procedure

Display of the result of downloads and visits, as well as the number of cited articles

Maximum dissemination of your research work

Submit your manuscript at: http://papersubmission.scirp.org/

Or contact ojbiphy@scirp.org 